\title{
TRABALHADORES E SINDICALISMO NO BRASIL: para onde foram os sindicatos?
}

\author{
Iram Jácome Rodrigues*
}

\begin{abstract}
Este artigo analisa o sindicalismo brasileiro no período mais recente e, ao mesmo tempo, discute o processo de associativismo sindical no país, a partir de alguns indicadores de sindicalização. Os dados deste estudo, construídos com base, principalmente, na Pesquisa Nacional por Amostra de Domicílios (PNAD) do Instituto Brasileiro de Geografia e Estatística (IBGE) mostram um deslocamento da sindicalização, seja no conjunto das regiões brasileiras, seja no que tange à questão de gênero, bem como na relação cidade/campo. E esse processo é mais visível no interior da maior central sindical brasileira, a CUT.

Palavras-chave: Trabalhadores. Sindicalismo brasileiro. Associativismo sindical. Central Única dos Trabalhadores (CUT).
\end{abstract}

\section{APRESENTAÇÃO}

Este texto é resultado da exposição, em mesa-redonda, organizada pelo colega Marco Aurélio Santana no Encontro da ANPOCS, em 2013, cujo tema foi "Para onde foram os sindicatos"? O presente artigo mantém os argumentos desenvolvidos naquela ocasião e traz uma atualização dos dados, bem como a incorporação de novas questões àquelas já debatidas.

Foram utilizados dados de sindicalização no Brasil da Pesquisa Nacional por Amostra de Domicílios (PNAD) do Instituto Brasileiro de Geografia e Estatística (IBGE), da aferição de representatividade das centrais sindicais do Ministério do Trabalho e Emprego (MTE) e da sindicalização da CUT.

No que tange aos dados da PNAD, o artigo analisa anos selecionados do período de 1992 a 2013. Neste caso, os anos de 1992, 1996, 1999, 2002, 2004, 2008, 2011 e 2013, vale dizer, um período de 22 anos. De outra

* Universidade de São Paulo. Departamento de Economia e Programa de Pós-Graduação em Sociologia.

Av. Prof. Luciano Gualberto, 908 - Prédio FEA 2 - sala 229. Cid. Universitária. Cep: 05508900 - São Paulo, SP - Brasil ijrodrig@usp.br parte, os números relacionados ao MTE e à CUT são recentes.

A principal questão da pesquisa ${ }^{1}$ diz respeito às repercussões, para o sindicalismo, do processo de interiorização do associativismo sindical no Brasil, que estão contidas nas seguintes questões: 1. Quais as implicações para a ação sindical de uma forte diminuição, em termos percentuais, da densidade sindical em áreas urbanas e seu crescimento no âmbito rural? 2. Em que medida, o aumento da taxa de sindicalização feminina e, em contrapartida, o decréscimo da densidade associativa masculina trará influência na atuação dos sindicatos no Brasil? 3. O que explicaria a diminuição da sindicalização no Sul/Sudeste e seu crescimento no Nordeste? 4. Quais as repercussões deste cenário na principal central sindical brasileira, a CUT?

A partir de meados de 1970 e, particularmente, com a retomada do movimento grevista pós-1978, o Brasil assistiu a mudanças ${ }^{1}$ Resultados parciais de projeto de pesquisa em andamento desenvolvido pelo autor e que conta com o apoio do CNPq. Agradeço ao colega Mario Henrique Guedes Ladosky os comentários e sugestões durante a elaboração deste trabalho e a Jonas Tomazi Bicev pelo tratamento estatístico dos dados quantitativos da Pesquisa Nacional por Amostra de Domicílios (PNAD) do Instituto Brasileiro de Geografia e Estatística (IBGE), utilizados na pesquisa. 
significativas no âmbito do trabalho, na ação sindical e na vida dos trabalhadores capitaneados por uma luta mais ampla por direitos no espaço da sociedade. O movimento dos trabalhadores, em especial uma parcela dos sindicatos e os movimentos sociais se confrontaram, naquele momento, com o Estado e, com isso, amplificaram suas reivindicações no interior da sociedade civil. Eram atores que, em sua dinâmica, expressavam a necessidade de uma presença mais marcante na vida do país, tanto no campo social quanto político. Vale dizer, não aceitavam uma cidadania de segunda classe, não se conformavam em serem, tão-somente, engrenagens da "máquina" (Rodrigues, 2011; Ladosky, 2009; Forte, 2014).

Como expressão das reivindicações trabalhistas e populares, naquele período, a Constituição de 1988 deu guarida a várias demandas dos trabalhadores. Isso ocorreu, segundo Leôncio Martins Rodrigues (1988; 1990), durante os trabalhos constituintes, muito mais em razão do forte lobby montado pelos sindicatos do que por uma mobilização mais efetiva dos trabalhadores no período.

De todo modo, não se pode obscurecer o fato de que, com a promulgação da nova Constituição, os sindicatos saíram fortalecidos e, por extensão, ainda que não no mesmo nível, L2 também os trabalhadores, por conseguirem : inscrever várias de suas demandas por novos Фं direitos na Carta Magna, principalmente no que concerne aos direitos sociais. E o que é क mais significativo: algumas dessas vantagens não faziam parte, originalmente, das reivindicações dos trabalhadores (Idem).

is José Ricardo Ramalho, em estudo que \& analisa os vinte anos da Constituição de 1988,

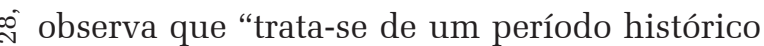

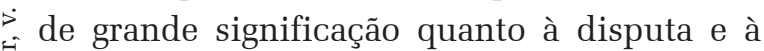
consagração de direitos sociais e do trabalho, capaz de proporcionar oportunidades para que se avaliem adequadamente o desempenho dos diversos setores ligados ao mundo do trabalho e das suas disputas políticas pela afirmação ou preservação de interesses e de leis, em um contexto aberto às pressões e contrapressões do jogo democrático" (Ramalho, 2009, p. 149). Noronha, (2009, p. 119-120), chama a atenção para 'os marcos políticos econômicos dos governos federais’, de Geisel a Lula. Para o autor, os referidos "marcos variavam significativamente entre as fases de liberalização política, de democratização, de consolidação da democracia (simbolizada pela Constituição de 1988) ou à fase de apelo por aumento da produtividade e competitividade brasileira no mercado internacional, iniciada no governo Collor e que, em grande parte, alterou toda agenda sindical dos anos 1990 em relação aos anos 1980”.

Os anos 1990 mudaram amplamente as condições do trabalho e do sindicalismo no Brasil: as transformações trazidas pelo processo de globalização, privatizações, abertura comercial, flexibilidade na produção e nas relações de trabalho, entre outros aspectos, colocaram a ação sindical na defensiva. Neste período, um tema que sobressai é o da defesa do emprego. Assim,

[...] insegurança e vulnerabilidade no trabalho são as principais características do que resultou do processo de reestruturação pelo qual passaram as atividades produtivas das sociedades industriais nas últimas três décadas. A exigência de maior competitividade entre as empresas introduziu estratégias de racionalização e redução de custos, com a flexibilização do emprego e o aumento do desemprego de longa duração. Postos de trabalho com perspectiva de estabilidade foram reduzidos drasticamente e novos tipos de contrato, mais precários e instáveis se tornaram prática comum nas empresas dos mais variados setores da economia. Nesse contexto, a instituição sindical ficou fragilizada, exigindo um constante esforço de reformulação para fazer frente ao perfil cada vez mais complexo do emprego, incluindo também ações no sentido de atender situações de trabalho informal e pobreza" (Ramalho e Rodrigues, 2009, p. 85-86).

\section{A PESQUISA}

No que tange à seleção das variáveis dos dados da PNAD, com o objetivo de analisar a taxa de sindicalização no Brasil, levando em 
consideração critérios de comparação internacional (Visser, 2013; Rodrigues, 1999), optou-se por verificar a taxa de sindicalização nas diferentes regiões do país e nos principais setores de atividade econômica, a partir da População Ocupada Adulta (POA), ou seja: da população com 18 anos ou mais, ocupada na semana de referência de realização da Pesquisa Nacional de Amostra de Domicílios (PNAD, entre os anos de 1992 e 2013). ${ }^{2}$

O critério adotado é mais abrangente do que o empregado pela literatura internacional, que considera, em geral, a taxa de sindicalização da população assalariada adulta. Isto é, trabalhadores cuja renda é obtida através de um salário regular. Nesse sentido, tal critério não leva em conta os trabalhadores rurais, predominantemente não assalariados (incluemse aí os pequenos proprietários e os trabalhadores autônomos), cuja presença entre os sindicalizados cresce num ritmo acelerado a partir dos anos 2000 .

Outra distinção analítica se deu em relação ao local dos domicílios participantes da pesquisa, os quais foram organizados em duas categorias: rurais e urbanas - regiões metropolitanas, áreas rurais e urbanas a partir da variável V4728 do código de situação censitária da PNAD.

De outra parte, com relação ao modo como foi construída a variável "Grandes Setores de Atividade Econômica” é necessário salientar que a mesma foi dividida em dois momentos (de 1992 a 1999; e de 2002 a 2013) em função das transformações nas classificações de atividades contidas na PNAD. Desse modo, entre 1992 e 1999, foram utilizadas as variáveis V4708 ("Atividade no trabalho principal

${ }^{2}$ Pesquisa amostral e domiciliar realizada pelo Instituto Brasileiro de Geografia e Estatística (IBGE), que, desde 1967, investiga as características socioeconômicas da população brasileira (como educação, trabalho, habitação, fecundidade, migração e outros). Possui periodicidade anual e utiliza como semana de referência, a última semana do mês de setembro de cada ano (IBGE, 2013). na semana de referência”) e V4709 ("Ramos de atividade no trabalho principal na semana de referência").

Por fim, entre 2002 e 2013, foi utilizada, apenas, a variável V4809 da PNAD ("Grupamentos de atividade principal do trabalho principal na semana de referência") e reagrupadas suas diversas categorias de forma mais ampla, conforme o modelo abaixo:
Variável Derivada (Gdes. Setores de Ativ. Econômica) 1. Agrícola

2. Indústria 3. Construção

4. Comércio

5. Serviços

\section{CENÁRIOS DA SINDICALIZAÇÃO NO BRASIL}

Quando se analisa a densidade sindical, ${ }^{3}$ a partir dos dados da PNAD, nas últimas

${ }^{3}$ A densidade sindical é um dos critérios para mensurar, por exemplo, a importância dos sindicatos. Pois, em tese, diz respeito à maior ou menor adesão dos trabalhadores às suas associações de classe. No entanto, este critério não é absoluto, logo, não pode ser tomado como único. Há muitos outros aspectos intervenientes que, muitas vezes, sobrepujam o critério mencionado. Um exemplo, nesse sentido, são as greves, mobilizações e outras ações sindicais. Cf., por exemplo, o estudo de Armando Boito Jr. e Paula Marcelino. O sindicalismo deixou a crise para trás? Um novo ciclo de greves na década de 2000. Caderno $\mathrm{CRH}$, Salvador, v. 23, n. 59, p. 323-338, Maio/Agosto. 2010. 
duas décadas, mais precisamente no período de 1992 a 2013 e, utilizando neste intervalo de tempo os anos de 1992, 1996, 1999, 2002, 2004, 2008, 2011 e 2013, ou seja, oito diferentes momentos, o que se observa é uma estabilidade, quando os dados se referem à População Economicamente Ativa (PEA): ${ }^{4}$ a sindicalização desse contingente representava 16\% em 1992 e, em 2013, se mantinha no mesmo patamar. Já no contingente da População Ocupada Adulta (POA), ${ }^{5}$ esse percentual oscila, respectivamente, de $19 \%$ para $16 \%$. É, entretanto, entre os assalariados, População Assalariada Adulta (PAA), ${ }^{6}$ dicalizado e, também, uma queda, em menor grau, da população ocupada adulta. No primeiro caso, há um decréscimo de seis pontos percentuais e, no segundo, de três. A hipótese para este processo, aparentemente, é que o menor decréscimo na densidade sindical da população ocupada adulta se relacionaria à entrada, no cômputo geral, dos trabalhadores rurais não assalariados, como mencionado anteriormente, que aumentaram substancialmente, em termos relativos, sua taxa de sindicalização, no período de 1992 a 2013, quando comparados com os trabalhadores rurais assalariados. que a queda da sindicalização, em termos percentuais, é maior. Nestes dois anos em questão, a taxa de sindicalização foi de 23\% (1992) para 17\% em 2013. Um decrésci-

Tabela 1 - Taxa de sindicalização no Brasil segundo a PEA, POA e PAA (\%) mo da ordem de seis pontos percentuais.

\begin{tabular}{lcccccccc}
\hline & $\mathbf{1 9 9 2}$ & $\mathbf{1 9 9 6}$ & $\mathbf{1 9 9 9}$ & $\mathbf{2 0 0 2}$ & $\mathbf{2 0 0 4}$ & $\mathbf{2 0 0 8}$ & $\mathbf{2 0 1 1}$ & $\mathbf{2 0 1 3}$ \\
\hline $\begin{array}{l}\text { Sindicalização } \\
\text { PEA }\end{array}$ & 16 & 16 & 16 & 16 & 17 & 17 & 17 & 16 \\
\hline $\begin{array}{l}\text { Sindicalização } \\
\text { POA }\end{array}$ & 19 & 18 & 17 & 18 & 19 & 19 & 18 & 16 \\
\hline $\begin{array}{l}\text { Sindicalização } \\
\text { PAA }\end{array}$ & 23 & 21 & 20 & 19 & 20 & 20 & 18 & 17 \\
\hline
\end{tabular}

Assim, segundo a PNAD, para o ano de 2013, o total da população ocupada adulta representava um contingente de 93,5 milhões de pessoas, dos quais 15,5 milhões eram sindicalizados, sendo 12 milhões nas áreas urbanas e 3,5 milhões nas áreas rurais. É importante ressaltar esta questão porque, de acordo com os dados apresentados neste estudo, para o período estudado, há um crescimens to expressivo da taxa de sindicalização entre os 㝏 trabalhadores rurais. No entanto, em termos abФं solutos, os sindicalizados nas cidades representam 77\% do total de sindicalizados no país, ao - passo que a sindicalização rural é apenas 23\% do associativismo sindical brasileiro.

De outra parte, quando se analisa o pe§íodo (1992-2013) há uma diminuição, em ter\& mos relativos, do contingente assalariado sin$\stackrel{\infty}{N}$

$\stackrel{4}{~} 4$ População Economicamente Ativa (PEA): população de 10 ố anos ou mais, ocupada na semana de referência ou desocupada com procura de trabalho ativa nos últimos 30 dias.

(PAA). população com 18 anos ou mais, ocupada na semana de referência, submetida a um empregador e remuneração regular, como os empregados com e sem carteira de trabalho assinada, militar, estatutários, empregados domésticos.
De outra parte, no que tange à população ocupada adulta, quando se analisa a sindicalização por região, no período em questão, observa-se outra novidade: queda acentuada dos sindicalizados na Região Sul, diminuição do associativismo na Região Sudeste, um processo de estabilidade nas taxas de sindicalização no Norte e Centro-Oeste e um razoável crescimento, nestes 22 anos, dadas as características da densidade sindical no Brasil, da sindicalização no Nordeste, de 16\% para 20\%. Esta é a única região do país onde ocorre um crescimento da taxa de sindicalização no período estudado, de acordo com a Tabela 2.

Com relação à questão de gênero, conforme Tabela 3, chama a atenção, no período 19922013, o declínio do associativismo masculino, que cai de 22\% em 1992 para 17\% em 2013. Já o feminino cresce muito pouco, nestes mesmos anos: de $14 \%$ para $16 \%$ (mesmo tendo chegado, em 2004 e 2008, a 18\%). De toda maneira, os dados estão mostrando que a curva da sindicalização feminina é, levemente, ascendente, já a masculina é claramente descendente.

Se, no conjunto dos assalariados brasi- 
Tabela 2 - Taxa de sindicalização no Brasil por Região (POA) (\%)

\begin{tabular}{lcccccccc}
\hline & $\mathbf{1 9 9 2}$ & $\mathbf{1 9 9 6}$ & $\mathbf{1 9 9 9}$ & $\mathbf{2 0 0 2}$ & $\mathbf{2 0 0 4}$ & $\mathbf{2 0 0 8}$ & $\mathbf{2 0 1 1}$ & $\mathbf{2 0 1 3}$ \\
\hline Norte & $\mathbf{1 4}$ & 14 & $\mathbf{1 4}$ & 12 & $\mathbf{1 4}$ & $\mathbf{1 6}$ & 16 & 14 \\
\hline Nordeste & 16 & 16 & $\mathbf{1 8}$ & $\mathbf{1 8}$ & 20 & 21 & 20 & 20 \\
\hline Sudeste & $\mathbf{1 8}$ & 18 & $\mathbf{1 7}$ & $\mathbf{1 7}$ & $\mathbf{1 8}$ & $\mathbf{1 8}$ & 16 & $\mathbf{1 5}$ \\
\hline Sul & 26 & 24 & 22 & 23 & 24 & 23 & 21 & 19 \\
\hline Centro-Oeste & 15 & 15 & 14 & $\mathbf{1 5}$ & $\mathbf{1 5}$ & $\mathbf{1 6}$ & 15 & 14 \\
\hline Total (Brasil) & $\mathbf{1 9}$ & 18 & $\mathbf{1 7}$ & $\mathbf{1 8}$ & $\mathbf{1 9}$ & $\mathbf{1 9}$ & 18 & $\mathbf{1 6}$ \\
\hline Fonte: PNAD
\end{tabular}

Fonte: PNAD/IBGE. Anos selecionados. Elaboração própria.

Tabela 3 - Taxa de sindicalização por gênero (Brasil, POA) (\%)

\begin{tabular}{lcccccccc}
\hline & $\mathbf{1 9 9 2}$ & $\mathbf{1 9 9 6}$ & $\mathbf{1 9 9 9}$ & $\mathbf{2 0 0 2}$ & $\mathbf{2 0 0 4}$ & $\mathbf{2 0 0 8}$ & $\mathbf{2 0 1 1}$ & $\mathbf{2 0 1 3}$ \\
\hline Masculino & 22 & 20 & 19 & 19 & 20 & 20 & 18 & 17 \\
\hline Feminino & 14 & 15 & 15 & 16 & 18 & 18 & 17 & 16 \\
\hline Total & 19 & 18 & 17 & 18 & 19 & 19 & 18 & 16 \\
\hline Fonte: PNAD/IBGE. Anos selecionados. Elaboração própria. & & & &
\end{tabular}

leiros, a sindicalização feminina está, praticamente, igual à masculina, conforme mostrou a Tabela 3, no que se refere à sindicalização no campo, o movimento é oposto, como ilustra a Tabela 4, taxa de sindicalização rural segundo o gênero. Neste caso, quando analisados os anos selecionados da série histórica (1992-2013), os dados mostram um crescimento continuado da sindicalização feminina, entre as residentes nas áreas rurais, até 2011, e uma pequena queda em 2013. Cabe ressaltar, no entanto, que as trabalhadoras rurais representavam $9 \%$ do percentual de sindicalizados, já em 2013 alcançaram o patamar de $27 \%$. De outra parte, os trabalhadores do campo representavam $22 \%$ dos sindicalizados em 1992, caem para 20\% nos dois anos seguintes e, depois, voltam a subir e, em 2013, alcançam 23\% dos sindicalizados, isto é, se mantêm, praticamente, estáveis, no período. Ainda que, em termos absolutos, o número de sindicalizados homens seja maior que o contingente feminino, percentualmente, o crescimento das mulheres foi mais significativo do que o dos homens, como mostra a tabela 4 e, possivelmente, esta é uma das razões pelas quais, em âmbito nacional, atualmente, haja praticamente uma igualdade de gênero, no que se refere à taxa de sindicalização.

A Tabela 5 e o Gráfico 1 apresentam o associativismo por zona de residência, isto é, se rural ou urbana. Os dados indicam um forte crescimento do percentual de sindicalizados rurais no período, mesmo que com queda expressiva no último ano da série (2013). De toda forma, há um crescimento de 17\% em 1992 para 24\% em 2013, tendo chegado a 27\% em 2011. Além disso, nas áreas urbanas há uma acentuada queda, no período estudado: de $23 \%$ para $15 \%$. Chama a atenção o fato de que os melhores anos da sindicalização urbana sejam os anos de 1992 e 1996, os anos iniciais da série. A promulgação da Constituição de 1988, certamente, desempenhou um papel nesse panorama. Uma vez que os servidores públicos passaram a ter direito a se sindicalizar, o que elevou, em muito, a sindicalização no espaço urbano, naquele momento. De outra parte, mesmo que tenha havido um crescimento, em números absolutos, nos anos de 1992, 1996, 1999, 2002, 2004 e 2008, o acréscimo percentual é muito diminuto, dado o crescimento total da população ocupada adulta, no mesmo período. Assim, mesmo que tenha ocorrido um crescimento nas áreas rurais, no

Tabela 4 - Taxa de sindicalização rural por gênero (Brasil, POA)

\begin{tabular}{lcccccccc}
\hline & $\mathbf{1 9 9 2}$ & $\mathbf{1 9 9 6}$ & $\mathbf{1 9 9 9}$ & $\mathbf{2 0 0 2}$ & $\mathbf{2 0 0 4}$ & $\mathbf{2 0 0 8}$ & $\mathbf{2 0 1 1}$ & $\mathbf{2 0 1 3}$ \\
\hline \multirow{2}{*}{ Masculino } & 1.875 .427 & 1.659 .076 & 1.795 .329 & 1.850 .033 & 2.189 .458 & 2.245176 & 2.150 .654 & 2.026 .101 \\
& $22 \%$ & $20 \%$ & $20 \%$ & $24 \%$ & $24 \%$ & $25 \%$ & $25 \%$ & $23 \%$ \\
\hline \multirow{2}{*}{ Feminino } & 460.323 & 656.907 & 917.846 & 1.150 .909 & 1.462 .198 & 1.620 .269 & 1.509 .395 & 1.403 .631 \\
& $9 \%$ & $13 \%$ & $16 \%$ & $23 \%$ & $26 \%$ & $29 \%$ & $30 \%$ & $27 \%$ \\
\hline \multirow{2}{*}{ Total } & 2.335 .750 & 2.315 .983 & 2.713 .175 & 3.000 .942 & 3.651 .656 & 3.865 .445 & 3.660 .049 & 3.429 .732 \\
(Rurais) & $17 \%$ & $17 \%$ & $19 \%$ & $23 \%$ & $25 \%$ & $26 \%$ & $27 \%$ & $24 \%$ \\
\hline Fonte: PNAD &
\end{tabular}

Fonte: PNAD/IBGE. Anos selecionados. Elaboração própria. 
Tabela 5 - Taxa de sindicalização nas áreas urbanas e rurais (Brasil, POA)

\begin{tabular}{lcccccccc}
\hline & $\mathbf{1 9 9 2}$ & $\mathbf{1 9 9 6}$ & $\mathbf{1 9 9 9}$ & $\mathbf{2 0 0 2}$ & $\mathbf{2 0 0 4}$ & $\mathbf{2 0 0 8}$ & $\mathbf{2 0 1 1}$ & $\mathbf{2 0 1 3}$ \\
\hline Áreas & 8.449 .366 & 8.847 .573 & 8.714 .068 & 10.258 .080 & 11.455 .842 & 12.861 .234 & 12.344 .801 & 11.991 .421 \\
Urbanas & $23 \%$ & $23 \%$ & $20 \%$ & $21 \%$ & $22 \%$ & $21 \%$ & $16 \%$ & $15 \%$ \\
\hline Áreas & 2.335 .750 & .3152983 & 2.713 .175 & 3.000 .942 & 3.651 .656 & 3.865 .445 & 3.660 .049 & 3.429 .732 \\
Rurais & $17 \%$ & $17 \%$ & $19 \%$ & $23 \%$ & $25 \%$ & $26 \%$ & $27 \%$ & $24 \%$ \\
\hline \multirow{2}{*}{ Total } & 10.785 .116 & 11.163 .556 & 11.427 .243 & 13.259 .022 & 15.107 .498 & 16.726 .679 & 16.004 .850 & 15.421 .153 \\
& $19 \%$ & $18 \%$ & $17 \%$ & $18 \%$ & $19 \%$ & $19 \%$ & $18 \%$ & $16 \%$ \\
\hline
\end{tabular}

Fonte: PNAD/IBGE. Anos selecionados. Elaboração própria.

Gráfico 1 - Taxa de sindicalização nas áreas rurais e urbanas (Brasil, POA)

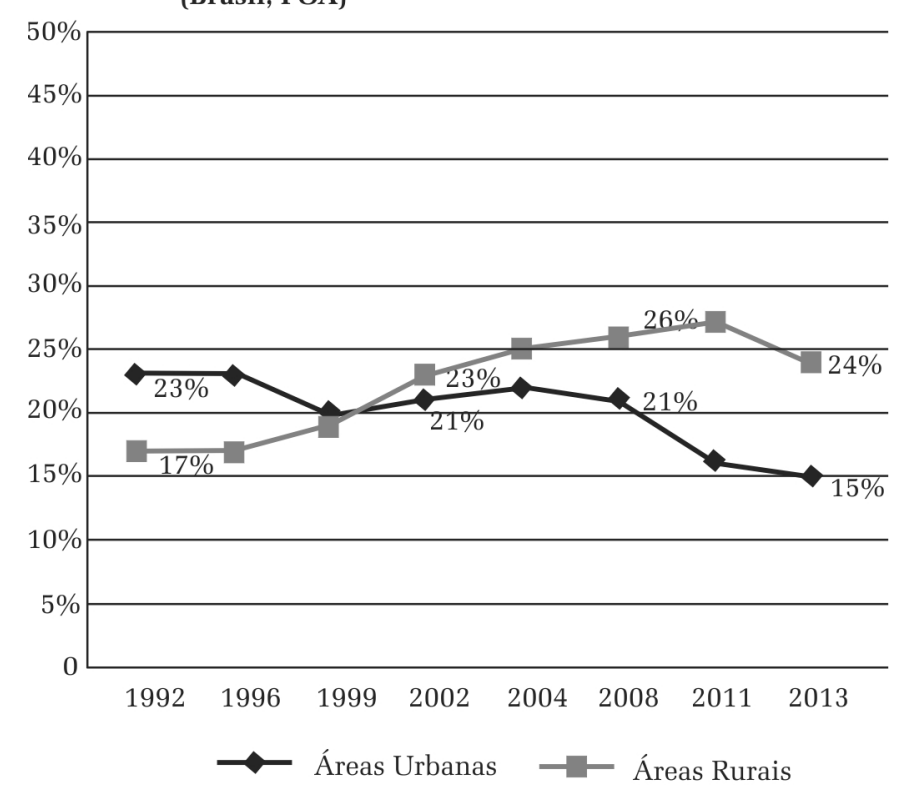

Fonte: PNAD/IBGE. Anos selecionados. Elaboração própria.

mesmo diapasão do setor urbano para os anos acima mencionados, percentualmente, esse 늘 processo foi maior entre os trabalhadores sini dicalizados no campo que aqueles sindicalizados da cidade. Também aqui há uma queda, em termos absolutos, para os anos de $2011 \mathrm{e}$ 2013. No que se refere à taxa de sindicalização, no entanto, a cidade tem mostrado uma $\dot{\sim}$ retração na densidade sindical e o setor rural, $\stackrel{2}{\wedge}$ ao contrário, um expressivo crescimento que, घं $\stackrel{\sim}{\sim}$ ano de 2013, começa, também, paulatinamenof te, a arrefecer.

Em alguma medida, a Tabela 6 e o Gráfico 2 , que tratam do associativismo vinculado aos setores de atividade econômica ilustram, de forma mais clara, o processo mencionado acima. ${ }^{7}$
O setor rural alcançou 16\% em 1992 e chegou a $27 \%$ em 2013; a indústria, que representava o maior percentual, no início da série histórica (30\%), caiu para 19\% no último ano (2013); além disso, o setor público, que possuía, em 1992, uma taxa de sindicalização de $27 \%$ e, neste ano, era o segundo setor com maior percentual de sindicalização, chegou ao final do período com uma perda diminuta de dois pontos percentuais. Os outros setores, serviços, comércio e construção se mantiveram, relativamente, estáveis. Em outras palavras, quando se olha para o início e final do período, respectivamente, 1992 e 2013, entre os setores agrícola e industrial, aquele, passou do terceiro lugar para primeiro, no que tange à taxa de sindicalização, já a indústria ficou em terceiro lugar. Os serviços públicos, de outra parte, mantiveram, em todo o período, a segunda posição, a despeito da pequena oscilação para baixo.

Por fim, a Tabela 7, dando conta da sindicalização por condição de assalariamento no setor de atividade agrícola, expressa, de forma mais contundente, uma das tendências da sindicalização no Brasil analisadas neste texto. Se, de um lado, em 1992, a sindicalização entre os assalariados agrícolas representava $25 \%$ dos associados rurais, aqueles não assalariados (neste caso, fundamentalmente trabalhadores

6 e os gráficos 1 e 2, no que se refere à sindicalização rural, é que na tabela 5 e no gráfico 1 se trata da sindicalização nas áreas rurais, ou seja, pressupõe que as pessoas residam e trabalhem no campo; já para a tabela 6 e o gráfico 2 , pressuporia atividades agrícolas, segundo a PNAD, também fora da área rural. Por isso, a pequena discrepância em termos do percentual de sindicalização em um e em outro caso. 
Tabela 6 - Taxa de sindicalização por setores de atividade econômica (Brasil, POA) (\%)

\begin{tabular}{lcccccccc}
\hline & $\mathbf{1 9 9 2}$ & $\mathbf{1 9 9 6}$ & $\mathbf{1 9 9 9}$ & $\mathbf{2 0 0 2}$ & $\mathbf{2 0 0 4}$ & $\mathbf{2 0 0 8}$ & $\mathbf{2 0 1 1}$ & $\mathbf{2 0 1 3}$ \\
\hline Agrícola & $\mathbf{1 6}$ & 17 & 19 & 24 & 26 & 29 & 29 & 27 \\
\hline Indústria & 30 & 26 & 23 & 21 & 24 & 23 & 23 & 19 \\
\hline Serviços Públicos & 27 & 28 & 27 & 28 & 29 & 28 & 26 & 25 \\
\hline Serviços & 12 & 12 & 11 & 11 & 11 & 11 & 10 & 10 \\
\hline Comércio & 11 & 10 & 9 & 11 & 12 & 12 & 11 & 10 \\
\hline Construção & 9 & 7 & 6 & 7 & 7 & 8 & 8 & 8 \\
\hline Outras atividades & 24 & 21 & 18 & 24 & 24 & 22 & 19 & 19 \\
\hline Total & 19 & 18 & 17 & 18 & 19 & 19 & 18 & 16 \\
\hline
\end{tabular}

Fonte: PNAD/IBGE. Anos selecionados. Elaboração própria.

Gráfico 2 - Taxa de sindicalização por setores de atividades econômicPerfazendo, assim, um crescimento

(Brasil, POA)

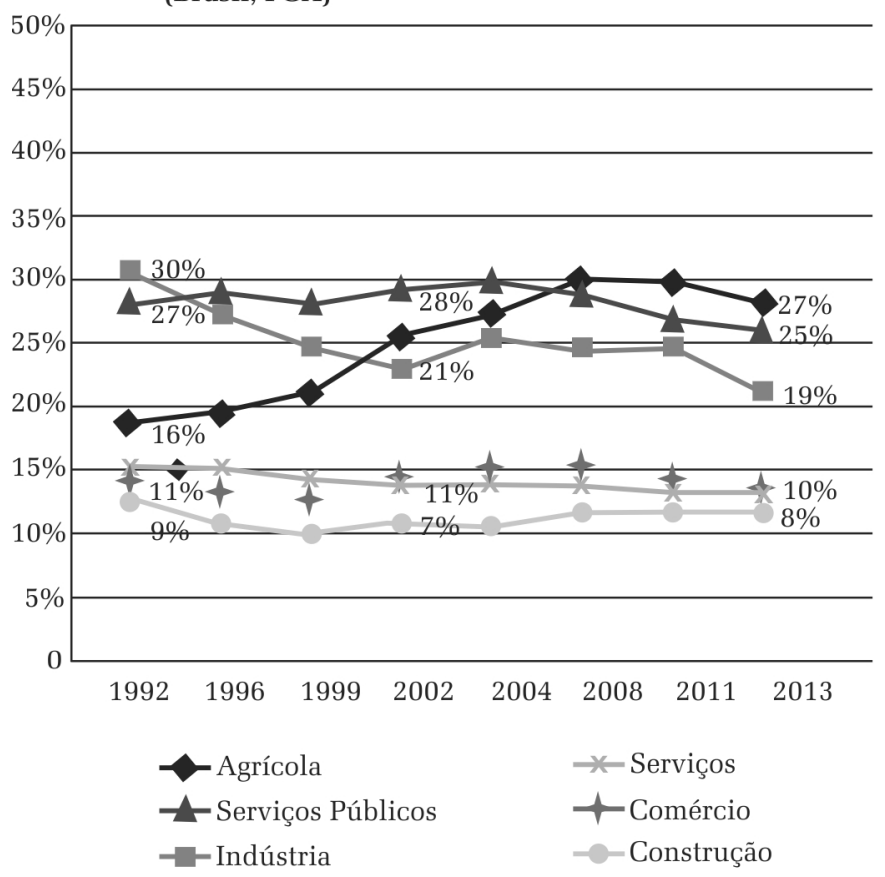

Fonte: PNAD/IBGE. Anos selecionados. Elaboração própria.

vinculados à pequena produção e/ou por conta própria, à agricultura familiar etc.), que representavam $75 \%$ do total dos sindicalizados rurais; de outro, 22 anos depois, em 2013, os assalariados que formavam aquele contingente assalariado perfaziam tão-somente $17 \%$, uma queda de oito pontos percentuais neste período e os trabalhadores não assalariados rurais chegavam a $83 \%$ dos associados no campo. de oito pontos percentuais no conjunto do associativismo entre os trabalhadores não assalariados. Nesse sentido, a perda de oito pontos percentuais dos trabalhadores assalariados com relação à sindicalização significou um ganho, na mesma proporção, para os rurais não assalariados, no que tange à densidade sindical. Vale dizer, de acordo com os dados da PNAD (2013), dos 3,5 milhões de sindicalizados rurais, $83 \%$ eram trabalhadores não assalariados. Como já discutido em outros estudos (Rodrigues e Ramalho, 2014; Rodrigues e Ladosky, 2015), esta tendência é uma das novidades do novo cenário que tem se desenhado no âmbito da sindicalização brasileira nas últimas décadas e, em especial, a partir dos anos 1990.

Em termos gerais, quais seriam as principais tendências explicitadas pelos dados da PNAD no período de 1992$2013 ?$

Em primeiro lugar e consoante com grande parte da literatura (Cardoso, 2014a; 2014b; 2013a; 2013b; Pichler, 2009; 2001; Zylberstajn e Rodrigues, 2002; Garcia e Dedecca, 2013) e, em que pese pequenas variações, de um modo geral, para o caso brasileiro, a propensão à sindicaliza-

Tabela 7 - Sindicalização agrícola por condição de assalariamento (Brasil, POA)

\begin{tabular}{l|ccc|ccc}
\hline & \multicolumn{3}{|c|}{$\mathbf{1 9 9 2}$} & \multicolumn{3}{c}{$\mathbf{2 0 1 3}$} \\
\hline & \multirow{2}{*}{ Assalariados } & $\begin{array}{c}\text { Não } \\
\text { Assalariados }\end{array}$ & Total & Assalariados & $\begin{array}{c}\text { Não } \\
\text { Assalariados }\end{array}$ & \multirow{2}{*}{ Total } \\
\hline \multirow{2}{*}{ Agrícola } & 556.282 & 1.692 .810 & 2.249 .092 & 590.428 & 2.933 .904 & 3.524 .332 \\
& $25 \%$ & $75 \%$ & $100 \%$ & $17 \%$ & $83 \%$ & $100 \%$ \\
\hline
\end{tabular}

Fonte: PNAD/IBGE. Anos selecionados. Elaboração própria. 
ção cresce com a idade, a renda e a escolaridade.

Em segundo lugar, a partir dos dados analisados, novas tendências se juntam às mencionadas acima: do ponto de vista regional, a única região no Brasil em que há crescimento da densidade sindical, ainda que pequena, é a região Nordeste. Já o Norte e o Centro-Oeste mantêm, para o período, suas taxas, praticamente, inalteradas e, nas regióes Sul e Sudeste, que eram aquelas com maiores taxas de associativismo em 1992, respectivamente, $26 \%$ e 18\%, em 2013 representavam apenas $19 \%$ e $15 \%$. Além disso, do ponto de vista da relação rural/urbana, ocorreu uma importante mudança: em 1992, a taxa de sindicalização entre os trabalhadores urbanos representava $23 \%$ contra $17 \%$ dos rurais. Ocorreu, no entanto, uma inversão desta tendência, passados 22 anos: em 2013, a taxa de sindicalização rural representava $24 \%$, ao passo que a urbana não passava de $15 \%$. Outro aspecto que chama a atenção nesta reconfiguração da sindicalização é o papel desempenhado pela questão de gênero e a sindicalização: se, no âmbito geral, ocorreu um deslocamento para baixo da sindicalização masculina, que passou de $22 \%$, em 1992, para $17 \%$, em 2013, no caso da feminina, houve um pequeno crescimento no período, de $14 \%$ para $16 \%$. Vale dizer, em 1992, havia uma diferença de oito pontos percentuais, a faVor dos homens, já em 2013 esta diferença caiu Фं para um ponto percentual, apenas. E, onde esta taxa de associativismo feminino tem crescido - com mais força, no período estudado, é na zona rural: a participação da sindicalização feminina em 1992 representava 20\% contra 80\% da is masculina; em 2013, os dados são, respecti\& vamente, $41 \%$ a $59 \%$. O que ilustra um cres今 cimento expressivo, no período, do associativismo feminino no meio rural. De outra parte, em termos gerais, a sindicalização nas áreas rurais, no período, que representava $17 \%$ em 1992, chegou a $24 \%$ em 2013, ao mesmo tempo em que ocorreu uma queda do associativismo sindical urbano, respectivamente, de 23\% para $15 \%$, conforme mencionado anteriormente.

\section{TENDÊNCIAS DA SINDICALI- ZAÇÃO NA CUT}

Esta seção do texto analisa alguns dados da própria CUT (2015), referentes ao tema da sindicalização: número de sindicatos e trabalhadores associados à central; setor de atividade econômica e densidade sindical e número de trabalhadores e percentual de sindicalização por região e setor de atividade.

O que chama a atenção nesses dados é que eles expressam uma tendência muito próxima daquela analisada quando da discussão dos dados da PNAD, principalmente no que se refere ao associativismo sindical rural.

É importante ressaltar que, de acordo com os dados oficiais da CUT, esta instituição possui, atualmente, quase quatro mil sindicatos filiados e cerca de oito milhões de associados no conjunto de suas entidades. De outra parte, de acordo com os dados de aferição da filiação às centrais sindicais do Ministério do Trabalho e Emprego (MTE, 2015), a taxa de sindicalização da CUT, no conjunto dos trabalhadores brasileiros, representava, respectivamente, $37 \%, 36 \%$ e $34 \%$, para os anos de 2012 , 2013 e 2014. Já a Força Sindical, para os mesmos anos, tinha, respectivamente, 14\%, 14\% e $12 \%$ e a UGT representaria, para os dois anos iniciais mencionados, $11 \%$ e teve uma elevação de um ponto percentual em 2014, chegando a $12 \%$. De todo modo, há uma pequena queda nas taxas de sindicalização das duas principais centrais sindicais no Brasil, quando se compara os anos de 2012-2014. Ainda que a CUT tenha crescido em números absolutos e a Força Sindical tenha decrescido neste quesito.

A Tabela 8 trata dos sindicatos e trabalhadores filiados à central por região e mostra que a principal concentração dos sindicatos cutistas (1.653), perfazendo $44 \%$ do total das entidades filiadas a esta central e com, aproximadamente, 3,5 milhões de associados, que equivalem a $42 \%$ de um contingente de quase oito milhões de sindicalizados, se situa no 
Tabela 8 - CUT - Sindicatos e trabalhadores sindicalizados por região

\begin{tabular}{lcc}
\hline & Sindicatos & $\begin{array}{c}\text { Trabalhadores } \\
\text { Sindicalizados }\end{array}$ \\
\hline Nordeste & 1.653 & 3.348 .818 \\
& $44 \%$ & $42 \%$ \\
Sudeste & 817 & 2.172 .284 \\
& $22 \%$ & $27 \%$ \\
Sul & 548 & 892.812 \\
& $14 \%$ & $11 \%$ \\
Norte & 396 & 875.176 \\
& $10 \%$ & $11 \%$ \\
Centro-Oeste & 367 & 633.397 \\
& $10 \%$ & 8.922 .487 \\
Total (Brasil) & 3.781 & $100 \%$ \\
\hline
\end{tabular}

Fonte: CUT, 2015. Elaboração própria.

Nordeste. O Sudeste surge em seguida, com $22 \%$ do total de sindicatos associados à CUT e 2,2 milhões de seus sindicalizados que perfazem $27 \%$ de seus membros. As regiões Sul e Norte têm, ambas, $11 \%$ dos sindicalizados a esta central. $^{8}$

Como veremos adiante, conforme a Tabela 9, que ilustra os números e percentuais de sindicalizados por setor de atividade, observa-se que a base da CUT, hoje, são os setores rural e público. Os trabalhadores rurais representam o maior contingente de sindicatos (1448), ou seja, cerca de $40 \%$ de todas as

Tabela 9 - CUT - Sindicatos e trabalhadores sindicalizados por setor de atividade

\begin{tabular}{lcc}
\hline & Sindicatos & $\begin{array}{c}\text { Trabalhadores } \\
\text { Sindicalizados }\end{array}$ \\
\hline \multirow{2}{*}{ Rural } & 1.448 & 3.589 .447 \\
& $38 \%$ & $45 \%$ \\
Serviço Público & 1.196 & 2.139 .868 \\
& $32 \%$ & $27 \%$ \\
Comércio/Serviços & 722 & 1.382 .961 \\
\hline \multirow{2}{*}{ Indústria } & $19 \%$ & $17 \%$ \\
\hline \multirow{2}{*}{ Total } & 415 & 810.211 \\
& $11 \%$ & $10 \%$ \\
\hline
\end{tabular}

Fonte: CUT, 2015. Elaboração própria.

${ }^{8}$ Nas tabelas 8, 9 e 10 os valores percentuais estão arredondados, sem as casas decimais. entidades filiadas à Central. Além disso, quase a metade (45\%) dos seus associados, 3,6 milhões de trabalhadores, tem origem no campo. O segundo grupo, em ordem de importância e representatividade, é o setor público com, respectivamente, praticamente $1 / 3$ dos sindicatos cutistas e $27 \%$ dos sindicalizados. O setor de comércio/serviços vem em terceiro lugar com $17 \%$ de associados (1,4 milhões) e, finalmente, o setor industrial tem um número diminuto, em termos percentuais, de sindicatos (11\%) e apenas $10 \%$ do total dos trabalhadores filiados à Central. Os dados da densidade sindical na indústria, quando comparados com as outras áreas de atividade econômica, no âmbito da CUT, mostram o quanto diminuiu o associativismo deste grupo de trabalhadores, que foi fundamental nos primeiros momentos da formação da central e, ao mesmo tempo, onde esta foi perdendo, paulatinamente, aderentes. O setor de comércio e serviços abrange, também, o conjunto do setor financeiro, e a ampla maioria das entidades sindicais deste é filiada à CUT. Esta é uma das razões para o peso da sindicalização no comércio/serviços.

De outra parte, o setor industrial foi aquele, onde, certamente, ocorreu a maior queda da sindicalização da central, seja em números absolutos, seja em termos relativos, nestes 32 anos de existência da CUT. É necessário ressaltar que estes dados mais gerais indicam uma tendência que está presente, com pequenas variações, na PNAD e, também, nos dados do Ministério do Trabalho e Emprego, no que diz respeito a esta questão.

A Tabela 10 apresenta os números e percentuais de trabalhadores sindicalizados por região e setor de atividade e, de certa forma, também corrobo- 
TRABALHADORES E SINDICALISMO NO BRASIL...

Tabela 10 - CUT - Número e percentual de sindicalizados por região e setor de atividade

\begin{tabular}{lcccccc}
\hline & Nordeste & Sudeste & Sul & Norte & $\begin{array}{c}\text { Centro } \\
\text { Oeste }\end{array}$ & Total \\
& 2.275 .044 & 321.036 & 182.503 & 648.515 & 162.349 & 3.589 .447 \\
Rural & $68 \%$ & $15 \%$ & $20 \%$ & $74 \%$ & $26 \%$ & $45 \%$ \\
\hline \multirow{2}{*}{ Serviço Público } & 638.819 & 781.129 & 357.469 & 96.875 & 265.576 & 2.139 .868 \\
& $19 \%$ & $36 \%$ & $40 \%$ & $11 \%$ & $42 \%$ & $27 \%$ \\
\hline \multirow{2}{*}{ Comércio/Serviços } & 338.458 & 623.816 & 185.737 & 55.740 & 179.210 & 1.382 .961 \\
& $10 \%$ & $29 \%$ & $21 \%$ & $6 \%$ & $28 \%$ & $17 \%$ \\
\hline \multirow{2}{*}{ Tndústria } & 96.497 & 446.303 & 167.103 & 74.046 & 26.262 & 810.211 \\
& $3 \%$ & $21 \%$ & $19 \%$ & $8 \%$ & $4 \%$ & $10 \%$ \\
\hline
\end{tabular}

Fonte: CUT, 2015. Elaboração própria.

ra os dados mais gerais sobre densidade sindical no Brasil, a partir dos dados da PNAD, e que também aparecem quando analisamos aqueles trabalhadores filiados à CUT, como mostrado acima: o peso dos setores rural e público. É como se, neste caso, esta central funcionasse como espelho das tendências da sindicalização brasileira. No Sudeste, Sul e Centro-Oeste, o serviço público, nas três esferas (municipal, estadual e federal) apresenta o maior percentual de sindicalizados à Central, respectivamente, $36 \%, 40 \%$ e $42 \%$. Os trabalhadores sindicalizados rurais são preponderantes nas duas outras regiões do país: Nordeste e Norte com, respectivamente, $68 \%$ e $74 \%$. De outra parte, em todas م as regióes, exceção à região Norte, o setor indusک trial é aquele que possui o menor contingente ه de associados, mesmo atingindo $21 \%$ e $19 \%$ de densidade sindical, respectivamente, no Sudes$\underset{s}{-}$ te e no Sul. De fato, no tocante à sindicaliza\ُ ção do conjunto da população ocupada adulta (POA), de acordo com a PNAD, a indústria reis presentava, em 1992, conforme já mencionado, \& $30 \%$ de sindicalizados e, foi caindo, paulatina今 mente, chegando, em 2013, com apenas 19\% (Cf. Tabela 6 e Gráfico 2 deste texto).

\section{CONSIDERAÇÕES FINAIS}

No âmbito das centrais sindicais, a CUT possui o maior número de entidades sindi- cais filiadas, 2.299 sindicatos, $21 \%$ do total de sindicatos brasileiros e, de outra parte, é a instituição que abriga mais de $1 / 3$ de todos os empregados sindicalizados no Brasil (34\%), segundo dados (MTE, 2015). No entanto, de acordo com os dados da Central, esses números seriam bem diferentes: quase quatro mil sindicatos e, aproximadamente, metade dos sindicalizados no país. De toda maneira, mesmo com certa discrepância, ${ }^{9}$ as duas fontes de dados (MTE e CUT) apontam a mesma tendência: sua maior representação está localizada na região Nordeste, com quase 3,5 milhões de associados, o que totaliza $42 \%$ do conjunto dos seus sindicalizados. Já o setor rural, no âmbito da Central, é responsável por, aproximadamente, $40 \%$ dos sindicatos filiados e quase a metade de seus associados (45\%). Em segundo lugar, aparece o setor público, com 1/3 dos sindicatos e $27 \%$ dos sócios cutistas. Isso signifi-

${ }^{9}$ Quando são comparados os dados do número de sindicatos filiados e de trabalhadores associados aos sindicatos há uma diferença muito grande entre o que mostra a CUT e o que é disponibilizado pela aferição do MTE. A principal explicação para esta discrepância se deve, principalmente, ao fato de o Ministério só contabilizar as entidades devidamente registradas e atualizadas em seu sistema, o que deve ocorrer a cada eleição sindical. Por esta razão um sindicato da CUT que, por algum motivo, não esteja com a documentacão em dia no MTE não será computado para os critérios de representatividade da Lei 11.648. No entanto, a mesma entidade constará no cadastro da CUT e terá todos os seus direitos de associada para indicação de delegados (as) aos congressos e plenárias se estiver cumprindo com suas atribuições estatutárias. Além disso, os pequenos sindicatos e, em particular, os rurais, dificilmente, enfrentam os trâmites burocráticos para se adequar a esta exigência ministerial. (Cf. Rodrigues e Ladosky, op. cit. 2015). 
ca dizer que $70 \%$ de suas entidades associadas são do setor rural e do setor público, e estes dois ramos abrigam $72 \%$ dos associados da Central. Conforme mencionado, anteriormente, sobre a questão rural na CUT, Rodrigues e Ladosky (op. cit. 2015) chamam a atenção para o fato de que a sindicalização no campo tem crescido muito nos últimos vinte anos e, em larga medida, esse associativismo esta relacionado àqueles setores que são preponderantes nas atividades ligadas à agricultura familiar. Em outras palavras, a densidade associativa no campo é, fundamentalmente, expressão do pequeno produtor familiar e não assalariado (Picolotto, 2011, dentre outros). Este processo, como já analisado em outros trabalhos, tem uma relação direta com as políticas de Estado e, também, de governos, e se relaciona com benefícios, no que tange à aposentadoria, pensões, serviços de saúde, serviços sociais, desde os anos 1970 e, no período mais recente, às políticas de crédito dirigidas ao agricultor familiar, o Programa Nacional de Fortalecimento da Agricultura Familiar (PRONAF), instituído em 1995 e que foi fortemente ampliado a partir dos anos 2000, bem como as políticas de inclusão social do governo federal nos últimos anos. (Rodrigues e Ramalho, 2014, op. cit. e Rodrigues e Ladosky, op. cit. 2015).

Os dados de pesquisa aqui apresentados ilustram, de certa forma, uma situação aparentemente surpreendente para o período estudado: evidenciam um crescimento acentuado, em termos percentuais, da sindicalização rural frente à urbana; e entre os rurais, ${ }^{10}$ esse maior acréscimo proporcional ocorre nos setores não assalariados, particularmente aqueles ligados à agricultura familiar; de outra parte, a taxa de sindicalização nacional feminina já é, praticamente, igual à masculina e, no campo, aque-

10 Não creio que a explicação desse fenômeno, apenas pelo modelo sindical corporativo, dê conta das várias facetas, por vezes, contraditórias desse processo. Para uma discussão do modelo corporativo de relações de trabalho no Brasil, cf., por exemplo, Leôncio Martins Rodrigues, "O sindicalismo corporativo no Brasil”. In: Partidos e Sindicatos, São Paulo: Ática, 1990 e Armando Boito Júnior, O Sindicalismo de Estado no Brasil, São Paulo: Unicamp/ Hucitec, 1991. la sobrepuja esta proporcionalmente; a única região onde há um crescimento da densidade sindical é o Nordeste; de outra parte, em termos nacionais, há uma tendência de queda da taxa de sindicalização na população ocupada adulta, entre 1992 e 2013; se a sindicalização rural, quando mensurada por gênero, se mantém praticamente estável, no que se refere aos homens, no entanto, cresce, percentualmente, com relação às mulheres de 9\% para 27\%, no período em questão; com relação à sindicalização por setores de atividade, chama a atenção o fato de que, se o setor público, de serviços, comércio e construção mantêm, com pequenas oscilações, estabilidade, os trabalhadores agrícolas, que em 1992 tinham uma taxa de sindicalização de 16\%, chegaram, em 2013, a $27 \%$, direção inversa àquela trilhada pelos trabalhadores da indústria, respectivamente, $30 \%$ e $19 \%$.

Quando são comparados os dados de sindicalização da PNAD com os associados da CUT, estas tendências, de certa maneira, se reafirmam ainda mais fortemente. Do ponto de vista regional, atualmente, o Nordeste congrega, de um lado, o maior número de sindicatos cutistas (44\%) e $42 \%$ dos sócios da Central, seguido da região Sudeste. De outra parte, o setor rural representa $38 \%$ dos seus sindicatos e $45 \%$ dos associados, seguidos pelo setor público. Nas regiões Nordeste e Norte, como já assinalado, a esmagadora maioria dos associados à CUT é rural, ao passo que, no Sudeste, Sul e Centro-Oeste, o maior contingente de sindicalizados é oriundo do setor público. Além disso, no âmbito da CUT, estes dois setores somados representam $70 \%$ das entidades filiadas e $72 \%$ dos seus associados. Se levarmos em conta que parcela ponderável dos rurais sindicalizados é agricultor familiar, pequeno produtor etc. a questão fica ainda mais complexa.

O Brasil é, hoje, um país predominantemente urbano. A população rural é muito pequena, quando comparada com aquela que habita a cidade. Nesse sentido, até onde se sustentaria, no médio prazo, uma tendência de cres- 
cimento da densidade sindical, de certa forma, apoiada na interiorização do associativismo, no rural e, entre estes, aqueles que são trabalhadores não assalariados? Os dados já começam a demonstrar certo "esgotamento" desse crescimento, haja vista a tendência à queda nesse processo, a partir de 2013, depois de sucessivos aumentos da sindicalização rural.

À medida que a principal central sindical brasileira, a CUT, é representativa, principalmente, do setor rural e do setor público, que concentram mais de $70 \%$ de seus associados, e o setor industrial perfaz apenas 10\% dos seus sindicalizados, qual o futuro para o sindicalismo-CUT e, por extensão, para o conjunto do sindicalismo no Brasil, nesse processo de reconfiguração do associativismo sindical em nosso país, apontados por esta pesquisa?

Recebido para publicação em 17 de junho de 2015 Aceito em 05 de agosto de 2015

\section{REFERÊNCIAS}

BOITO JR. Armando. O Sindicalismo de Estado no Brasil. São Paulo: Unicamp/Hucitec, 1991.

; MARCELINO, Paula. O sindicalismo deixou a crise para trás? Um novo ciclo de greves na década de 2000. Caderno CRH, Salvador, v. 23, n.59, p. 323-338, Maio/Ago. 2010.

CARDOSO, Adalberto Moreira. Os sindicatos no Brasil. Nota técnica. IPEA, 56, fev. 2014a, p. 21-27.

. Sindicato no Brasil: passado, presente e futuro. In: CATTANI, Antonio David (Org.). Trabalho: horizonte 2021. Porto Alegre: Escritos Editora, 2014b.

离

Para onde foram os sindicatos? In: KREIN et al. Regulaçãa do trabalho e instituições públicas. São Paulo, Perseu Abramo, 2013a, v. 1.

$\dot{8}$

in

- Ensaios de sociologia do mercado de trabalho brasileiro. Rio de Janeiro: FGV, 2013b.

\& CUT - Central Única dos Trabalhadores. Perfil da base sindical. São Paulo: CUT, 2015.

$\stackrel{\infty}{\mathrm{N}}$

FORTE, Fernanda. Os dilemas da CUT no início do século

$>$ XXI: rumo a uma nova institucionalização sindical? Tese de doutorado. Faculdade de Economia da Universidade de Coimbra, 2013.

GARCIA, Carlos Henrique; DEDECCA, Claudio Salvadori. A heterogeneidade do mercado de trabalho e a desigualdade de Janeiro, v. 3(5), junho 2013, p. 223-243.

Z LADOSKY, Mario Henrique Guedes. A CUT no Governo Lula: da defesa da "liberdade e autonomia" à reforma Uै sindical inconclusa. Tese de doutorado, Faculdade de Filosofia, Letras e Ciências Humanas (FFLCH), Universidade de São Paulo, 2009.

MARTINS RODRIGUES, Leôncio. Destino do Sindicalismo. São Paulo: Edusp, 1999.

. Partidos e Sindicatos. São Paulo: Ática, 1990.

. O poder sindical na nova Constituição. In: Os direitos sociais e trabalhistas na Constituição de 1988. ABRH- Nacional, São Paulo, outubro de 1988. Terra, 1990

CUT: os militantes e a ideologia. São Paulo: Paz e

MTE - Ministério do Trabalho e Emprego. Dados aferição sindicalização. Brasília: MTE, 2015.

PICHLER, Walter Arno. Revitalização do associativismo sindical no Brasil nos anos 2000. In: HORN, Carlos Henrique; SILVA, Sayonara G. C. L. da (Orgs.). Ensaios sobre sindicatos e reforma sindical no Brasil. São Paulo: LTr, 2009.

PICHLER, Walter Arno. Tendências da sindicalização no Brasil: 1992-2009. Indicadores Econômicos FEE, Porto Alegre, v. 38, n. 3, 2001, p. 37-46.

PICOLOTTO, Everton Lazzaretti. As Mãos que alimentam a nação: agricultura familiar, sindicalismo e política. Tese de doutorado, Desenvolvimento, Agricultura e Sociedade, UFRRJ, 2011.

RAMALHO, José Ricardo. "Trabalho, direitos sociais e sindicatos na Constituição de 1988 - duas décadas de acirrada disputa”. In: Ruben George Oliven; Marcelo Ridenti; Gildo Marçal Brandão (Orgs.). A Constituição de 1988 na vida brasileira. São Paulo: Hucitec, 2008.

; RODRIGUES, Iram Jácome. Trabalho, flexibilidade e terceirização: o caso da indústria automotiva. In: DAU, Denise Motta; RODRIGUES, Iram Jácome; CONCEIÇÃO, Jefferson José (Orgs.). Terceirização no Brasil: do discurso da inovação à precarização do trabalho. São Paulo: Annablume, 2009.

RODRIGUES, Iram Jácome. Sindicalismo e política: a trajetória da CUT (1983-1993). São Paulo: LTr, 2a . Edição, 2011.

; RAMALHO, José Ricardo. Novas configurações do sindicalismo no Brasil? Uma análise a partir do perfil dos trabalhadores sindicalizados. Contemporânea - Revista de Sociologia da UFSCar. São Carlos, v. 4, n. 2, jul-dez 2014, p. 381-403.

; LADOSKY, Mario Henrique Guedes. Paradoxos do sindicalismo brasileiro: a CUT e os trabalhadores rurais. Lua Nova, São Paulo, n. 95, 2015, p. 85-139.

VISSER, Jelle. Data Base on Institutional Characteristics of Trade Unions, Wage Setting, State, Intervention and Social Pacts,1990-2011 (ICTWSS) Amsterdam Institute for Advanced Labour Studies AIAS, University of Amsterdam. 2013.

ZYLBERSTAJN, Hélio; RODRIGUES, Iram Jácome. Perfil socioeconômico da base sindical brasileira. Texto para discussão (FIPE-USP), n. 20/2002. 


\section{WORKERS AND UNIONISM IN BRAZIL: where did the labor unions go?}

\section{Iram Jácome Rodrigues}

This article analyzes contemporary Brazilian unionism and, at the same time, discusses the process of affiliation to unions in the country from a few union indicators. Data from this study, mainly based on the National Research by Home Samples (PNAD) of the Brazilian Institute of Geography and Statistics (IBGE), show a movement from the unions, regarding all Brazilian regions, gender issues, and the city/countryside relationship. This process is more apparent inside the main union center in Brazil, the CUT (Workers Union Center).

KeYwords: Workers. Brazilian unonism. Union affiliation. Wokers Union Center (CUT).

\section{TRAVAILLEURS ET SYNDICALISME AU BRÉSIL: où sont donc les syndicats?}

Iram Jácome Rodrigues

Cet article analyse le syndicalisme brésilien d'une période plus récente et examine, en même temps, le processus d'association syndicale dans le pays à partir de quelques indicateurs de syndicalisation. Les données de cette étude basée essentiellement sur la Recherche Nationale par Échantillonnage à Domicile (PNAD) de l'Institut Brésilien de Géographie et des Statistiques (IBGE) démontrent un déplacement de la syndicalisation, que ce soit dans l'ensemble des régions brésiliennes ou en ce qui concerne la question de genre, tout comme dans la relation ville/campagne. Ce processus est encore plus visible au sein de la plus grande confédération syndicale brésilienne, la CUT.

Mots-CLÉs: Travailleurs. Syndicalisme brésilien. Association syndical. Centrale Unique des Travailleurs (CUT).

Iram Jácome Rodrigues - Doutor em Sociologia. Professor Associado (Livre-Docente) do Departamento de Economia da Universidade de São Paulo e do Programa de Pós-Graduação em Sociologia da Universidade de São Paulo (PPGS-USP). Pesquisador do CNPq. Atua na área de Sociologia, com ênfase em Sociologia do Trabalho, principalmente nos seguintes temas: ação coletiva, sindicalismo e desenvolvimento regional; relações de trabalho e organização de interesses; sindicalismo e política; trabalho e sindicalismo. Autor e coautor de várias publicações em revistas científicas e livros. Entre estes, Sindicalismo e Política: a trajetória da CUT (1983-1993) (2 ${ }^{a}$ ed. São Paulo: Ltr, 2011); Trabalho e Sindicato em antigos e novos territórios produtivos (São Paulo: Annablume, 2007); Trabalho e ação sindical no Brasil contemporâneo (São Paulo: Annablume, 2015). 
